\title{
Simulating Smoke Transport in Large Scale Enclosure Fires Using a Multi-Particle-Size Model
}

\author{
XIAOQIN HU, ZHAOZHI WANG, FUCHEN JIA, EDWIN R. GALEA, and MAYUR K. PATEL \\ Fire Safety Engineering Group \\ University of Greenwich \\ London SE10 9LS UK
}

\begin{abstract}
In computational fluid dynamics (CFD) based fire simulation, the particle-laden smoke is usually assumed to be in a gaseous state. This is due to the assumption that most of the smoke particles have diameters less than about $2.0 \mu \mathrm{m}$ and so their settling velocities can be ignored compared with the intensive turbulent fire gas flow. This simplification can lead to severely under-predicted smoke levels in the lower layer at remote locations from the fire source. This problem is addressed in this paper through the development of a multiparticle-size model which takes into consideration the uneven mass size distributions of smoke particles. The model divides the smoke particles into three groups with various diameter ranges. The transport of smoke particles in each group is represented by a governing equation, in which the gravitational force is addressed by adding a correction into the convection term. The efficiency of the model to reproduce smoke transport is demonstrated by simulating a large scale PVC cable fire experiment conducted in a long corridor. Compared with a conventional smoke transport model, the new model is shown to be better able of reproducing the measured experimental smoke data and the recorded visibilities.
\end{abstract}

KEYWORDS: smoke transport, smoke particle, CFD, drift flux model, large-scale enclosure fire.

\section{NOMENCLATURE LISTING}

\begin{tabular}{|c|c|c|c|}
\hline$A_{p}$ & area of a particle $\left(\mathrm{m}^{2}\right)$ & $u$ & velocity $(\mathrm{m} / \mathrm{s})$ \\
\hline$C_{\text {smoke }}$ & smoke concentration $\left(\mathrm{kg} / \mathrm{m}^{3}\right)$ & $v$ & kinematics viscosity $\left(\mathrm{m}^{2} / \mathrm{s}\right)$ \\
\hline$C_{D}$ & drag coefficient & $v_{s}$ & settling velocity $(\mathrm{m} / \mathrm{s})$ \\
\hline$D$ & $\begin{array}{l}\text { Brownian diffusion coefficient } \\
\left(\mathrm{m}^{2} / \mathrm{s}\right) \text { or particule diameter }(\mathrm{m})\end{array}$ & $V_{p}$ & volume of a particle $\left(\mathrm{m}^{3}\right)$ \\
\hline$g$ & gravitational acceleration $\left(\mathrm{m} / \mathrm{s}^{2}\right)$ & $Y$ & mass fraction \\
\hline$I_{\lambda}$ & light intensity $\left(\mathrm{cd} / \mathrm{m}^{2}\right)$ & Greek & \\
\hline$K$ & extinction coefficient $(1 / \mathrm{m})$ & $\varepsilon_{\mathrm{p}}$ & particle eddy diffusivity $\left(\mathrm{m}^{2} / \mathrm{s}\right)$ \\
\hline$K_{m}$ & $\begin{array}{l}\text { specific smoke extinction } \\
\text { coefficient }\left(\mathrm{m}^{2} / \mathrm{kg}\right)\end{array}$ & $\rho$ & density $\left(\mathrm{kg} / \mathrm{m}^{3}\right)$ \\
\hline$L$ & distance $(m)$ & $\Gamma$ & effective exchange coefficient $\left(\mathrm{m}^{2} / \mathrm{s}\right)$ \\
\hline$R_{D}$ & particle Reynolds number & $\Phi$ & fluid variable \\
\hline$S$ & visibility $(\mathrm{m})$ & subscri & \\
\hline$S_{\Phi}$ & source term & $a$ & air \\
\hline$t$ & time $(\mathrm{s})$ & $i$ & particle group number \\
\hline$\vec{U}$ & velocity vector & $p$ & particle \\
\hline
\end{tabular}

\section{INTRODUCTION}

Fire statistics suggest that the most common identified cause of death during fire incidents is being overcome by fire effluent, in particular toxic gases contained in fire smoke [1]. The hazards presented by fire smoke are threefold. Firstly, by reducing visibility smoke can delay escape of the occupants and cause them to be exposed to the products of combustion for an unacceptably long period of time. Secondly, the large number of particles within the fire smoke may absorb toxic species which when inhaled may be a threat to exposed occupants. Full-scale fire tests have demonstrated that the mass fraction of $\mathrm{HCl}$ in soot particles in a fire involving PVC carpet is as high as $10 \%$ [2]. Finally, inhalation of the particle-laden smoke makes breathing difficult and may damage the lungs of those exposed [3]. Therefore, for life safety assessment it is important to accurately predict smoke levels within compartment fires. 
Computational fluid dynamics (CFD) based fire models are now popular methods for predicting smoke transport. In most of the models, smoke is often either ignored, such as the methods using oxygen depletion or temperature [4] to predict smoke levels, or simply treated as being in a gaseous state [5,6], assuming smoke movement in the same manner of other gaseous combustion products. However, this simplification is sometimes possibly invalid as smoke is a particle phenomenon [7]. Unlike common fire gases, gravitational settling and deposition are among the most important characteristics that distinguish particles from gases and both effects become increasingly important as particle size increases [8]. For smoke particles with diameters greater than about $4.5 \mu \mathrm{m}$, gravitational forces cannot be ignored [9]. Within fire smoke, the number of particles with diameters between $4.5 \mu \mathrm{m}$ and $10 \mu \mathrm{m}$ is considerably less than that of small particles with size less than $4.5 \mu \mathrm{m}[7,10]$. However, they account for a non-negligible proportion of the total smoke mass over the spectrum of particle sizes for a wide range of building materials $[3,11]$. Therefore, the settling velocity for large particles should be considered in smoke transport simulations, in particular within large enclosures.

By considering the effect of settling velocity on smoke movement, Chow et al. [12] developed a model using the Lagrangian approach to study smoke movement. However, the computational cost of the Lagrangian method limits its application in smoke simulations within large-scale fire enclosures as statistically stable particle concentrations require a large number of particle tracks [13]. Compared with the expensive computational requirement of the Lagrangian method, the computational cost of the Eulerian method for simulating particle movement is significantly lower. In [13], within the framework of the Eulerian method, the settling velocity effect of particles is added into the convection term of the particle conservation equation. The settling velocities of particles are calculated using the drift flux model. This model has been widely used to simulate the transport of particles within buildings $[8,13]$.

In the remainder of this paper we introduce a multi-particle-size model which is an Eulerian method in nature. The model takes into consideration the gravitational settling of smoke particles by adopting the drift flux method. A large-scale enclosure PVC cable fire is simulated with the new smoke model. The light extinction coefficient, visibility and smoke filling time within the enclosure calculated from the predicted smoke concentrations are compared with measured values and observations from the fire test.

\section{MULTI-PARTICLE-SIZE MODEL}

Conventional smoke models treat smoke as a gas. This simplification to the particulate nature of smoke is reasonable in regions near to the fire, where the gravitational settling of particles can be ignored compared with the strong momentum of the flow. However, flow momentum decays and the gravitational settling becomes important at remote regions from the fire source. Thus the treatment of smoke as a gas can result in poor predictions of smoke levels at remote locations in fire scenarios in which a non-negligible amount of large particles are generated. A methodology within a CFD framework to address the effect of particle sizes on smoke movement is proposed in this section.

The basic CFD framework used in the present study is the SMARTFIRE software $[6,14,15]$. In field modeling, the fluid is governed by a set of three-dimensional partial differential equations. This set consists of the continuity equations, the momentum equations in three space dimensions, the energy equation, the user equations for mass and mixture fraction, the equations for turbulence model, in this case the $k-\varepsilon$ model which incorporates buoyancy modification. The generalized governing equation for all variables is expressed in the following form:

$$
\frac{\partial \rho \Phi}{\partial t}+\operatorname{div}(\rho \vec{U} \Phi)=\operatorname{div}\left(\Gamma_{\Phi} \nabla \Phi\right)+S_{\Phi}
$$

where $\Phi$ represents the fluid variable; $\rho$ and $\vec{U}$ are the local density and velocity vector; $\Gamma_{\Phi}$ is the effective exchange coefficient of $\Phi ; S_{\Phi}$ represents the source term for the corresponding variable $\Phi$ and time $t$ is an independent variable. In SMARTFIRE, the smoke was set as a scalar. The conventional smoke model in which smoke is assumed to be in the gaseous state is called 'conventional model' henceforth. Before introducing the multi-particle-size model, the drift flux model is briefly described. 


\section{Drift Flux Model}

Due to gravitational settling, air and particles move at different velocities. The drift flux model [13] integrates the gravitational settling, convection and diffusion effects of particles into the governing equation of particles. In the drift flux model, the governing equation for particle transport in turbulent flow field is expressed as:

$$
\frac{\partial \rho Y}{\partial t}+\operatorname{div}\left(\rho\left(\vec{U}+v_{s}\right) Y\right)=\operatorname{div}\left(\rho\left(D+\varepsilon_{p}\right) \nabla Y\right)+S_{Y}
$$

where $Y$ is the particle mass fraction, $v_{s}$ is the particle settling velocity, $\varepsilon_{p}$ is the particle eddy diffusivity and $D$ is the Brownian diffusion coefficient. The particle eddy diffusivity $\varepsilon_{p}$ is assumed to equal the fluid turbulent viscosity, $v_{t}$, in enclosure fire environments [16]. The settling velocity of a particle could be derived by equaling the fluid drag force on the particle with the gravitational force and given by:

$\left|v_{s}\right|=\left[\frac{2\left(\rho_{p}-\rho_{a}\right) g V_{p}}{C_{D} A_{p} \rho_{a}}\right]^{1 / 2}$

where $\rho_{p}$ and $\rho_{a}$ are the density of particle and air respectively, $g$ is the gravitational acceleration, $V_{P}$ and $A_{P}$ are the volume and area of a particle respectively. $C_{D}$ is the drag coefficient and can be calculated according to the Stokes's law [17] as:

$C_{D} \approx \frac{24}{R_{D}}=\frac{24 v}{u D}$

Where $R_{D}, u, \mathrm{D}$, and $v$ are particle Reynolds number, velocity, particle diameter, and kinematic viscosity respectively. Equation 4 is used inside the Stokes Range $\left(R_{D}<1\right)$.

There are several assumptions for the drift flux model [13]:

A. The effect of particles on turbulence is not considered, as it is believed that the low particle loadings and comparatively small particle settling velocities have a negligible effect compared to the high inflow turbulence levels.

B. The particle size distribution is not altered by coagulation.

C. The body force due to particle/fluid density difference is neglected.

\section{The Multi-Particle-Size Model}

Based on the drift flux model, a multi-particle-size model is developed for smoke particle transportation. Figure 1 shows particle mass distributions in terms of particle size for a wide range of building materials, which were experimentally derived in [3]. Similar smoke particle mass size distributions for other materials can be found in [7,10-11]. The smoke particle sizes vary between $0.01 \mu \mathrm{m}$ and $10 \mu \mathrm{m}$. Such a large variation in the particle size makes it difficult to simulate the movement of smoke as the particle size has a significant influence on the manner of particle movement.

Figure 2 shows the settling velocity against particle size derived from Eq. 3. The gravitational settling velocity gradually increases with increasing particle size. For particles with sizes less than $2.0 \mu \mathrm{m}$, the settling velocity is no more than $10^{-5} \mathrm{~m} / \mathrm{s}$, which can be ignored compared with the velocity of the air flow within fire enclosures. 


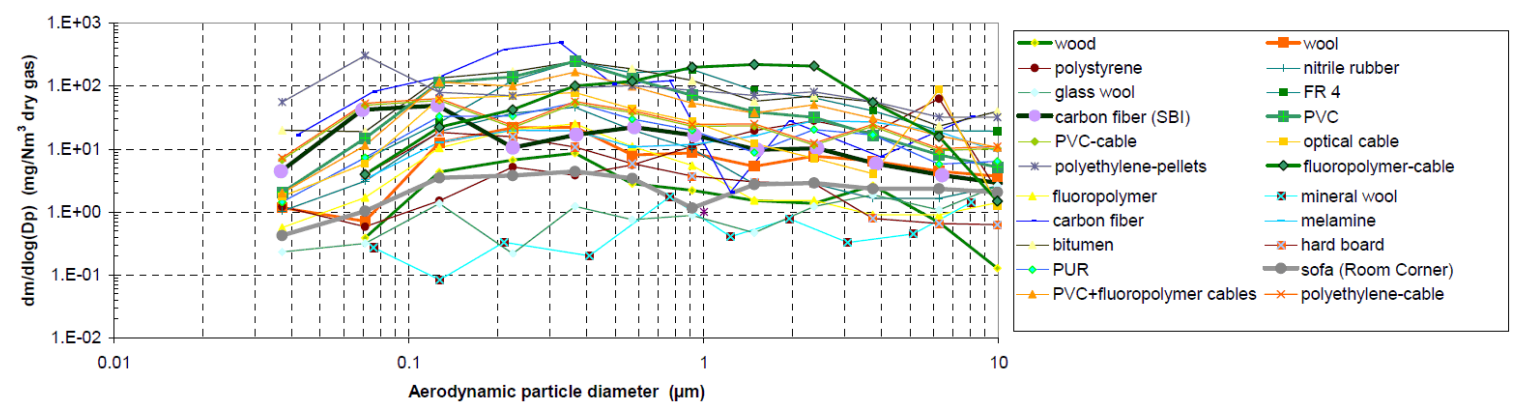

Fig. 1. Smoke particle mass size distribution [3].

However, the settling velocity cannot be completely ignored for large particles. Firstly, as seen in Fig. 2, the settling velocities are approximately $10^{-4} \mathrm{~m} / \mathrm{s}$ and $10^{-3} \mathrm{~m} / \mathrm{s}$ for particles with sizes of $4.5 \mu \mathrm{m}$ and $10 \mu \mathrm{m}$ respectively. This velocity magnitude is comparable with the velocity in the gravitational direction of air flow in the remote locations in fire enclosures. At this level of the settling velocity, its accumulative effect over a long period of time can be significant within a large fire enclosure as the residence time of smoke particles within the enclosure can be very long. Secondly, although the number of particles in the fire smoke decreases rapidly with the increase of particle size, the mass distribution of smoke against particle size is more flat (see Fig. 1). For a large variety of materials, the mass fraction of large particles is very high. For example, the mass fractions of particles with sizes between $2 \mu \mathrm{m}$ and $7 \mu \mathrm{m}$ is approximately 0.31 and the value for particles between $7 \mu \mathrm{m}$ and $10 \mu \mathrm{m}$ is approximately 0.25 for smoke from melamine. For PVC cable, although the mean particle size is only $0.14 \mu \mathrm{m}$, the mass fraction of particles with diameter sizes above $7 \mu \mathrm{m}$ is 0.06 . Therefore, the settling velocities of large smoke particles must be considered as they may account for a significant fraction of the total mass of smoke particles.

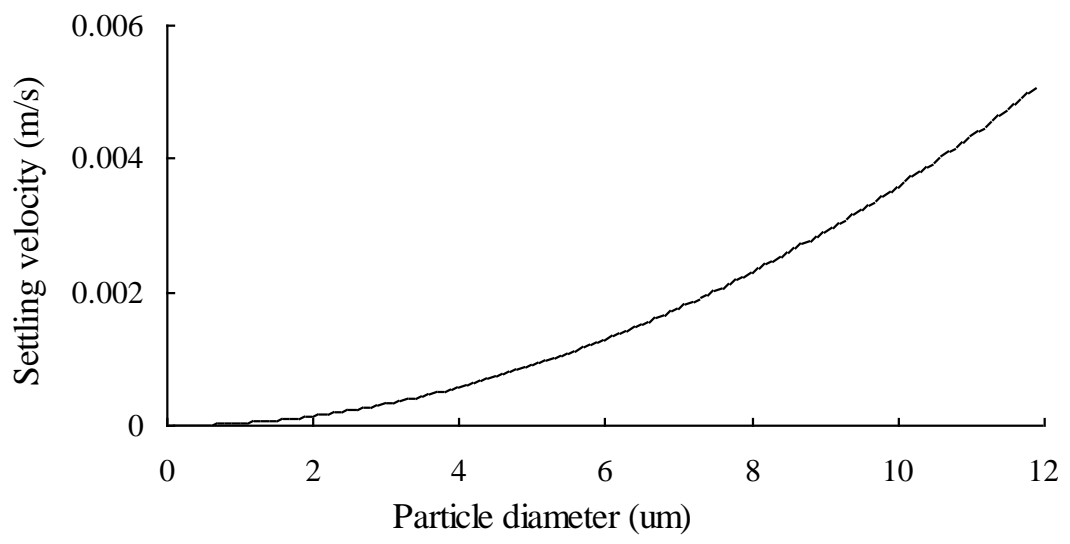

Fig. 2. Particle size vs. gravitational settling velocity.

To take into account the effect of particle size on gravitational settling velocity, smoke particles are divided into several groups according to their diameter sizes. The transport of the smoke particles in each group is defined by a governing equation in the form of Eq. 2. The volume and area of particles in Eq. 3 is determined by the average of the particle size of this group. Let $Y_{\mathrm{i}}$ denote the mass fraction of smoke group $i$ within a control volume. The smoke mass fraction in this control volume, $Y$, is then given by:

$Y=\sum Y_{i}$.

With this approach, the number of smoke groups and the criterion of group division need to be defined. The number of smoke groups should be determined by considering both the particle mass size distribution of the material in question and the variation of settling velocity vs. particle size (Fig. 2). As seen in Fig. 1, the distributions of particle sizes for most of the materials follow similar trends. Therefore, in this study, the 
smoke particles are simply divided into three groups with sizes of 0-2.0 $\mu \mathrm{m}, 2.0-7.0 \mu \mathrm{m}$ and above $7.0 \mu \mathrm{m}$ respectively. For the three groups, the mean diameters are $1.0 \mu \mathrm{m}, 4.5 \mu \mathrm{m}$ and $10 \mu \mathrm{m}$ respectively.

\section{LIGHT EXTINCTION AND VISIBILITY}

As the light extinction and visibility are common smoke properties, which are usually measured or recorded in fire experiments, their calculations using smoke concentrations are summarized here. The light extinction is the ratio of the light intensity, $I_{\lambda}$, passing through a distance of $L$ to the initial light intensity,

$I_{\lambda}^{0}$, which is a function of the smoke extinction coefficient $K$ [7]:

$I_{\lambda} / I_{\lambda}^{0}=e^{-K L}$

The smoke extinction coefficient $K$ is given by the specific extinction coefficient per unit mass $K_{m}$ $\left(7600 \mathrm{~m}^{2} / \mathrm{kg}\right)$ with:

$K=K_{m} C_{\text {smoke }}$

where $C_{\text {smoke }}$ is the concentration of smoke in $\mathrm{kg} / \mathrm{m}^{3}$.

With the smoke extinction coefficient, the visibility of signs is calculated with the empirical formula $[7,18]$

$S=C / K$

where $S$ is the visibility distance and constant $C$ takes the values of 8 and 3 for light emitting signs and light reflecting signs respectively. There are many factors that affect the predicted visibility such as smoke concentrations and the background lighting [5]. The constant 8 for $C$ is derived from the condition of illumination under $3 \mathrm{~cd} / \mathrm{m}^{2}$, which is the illumination of the exit sign.

When smoke concentration is not available, light extinction and visibility can be estimated from temperature levels as the approach used in [4].

\section{SIMULATIONS AND RESULTS}

In this section, smoke movement from a large scale PVC cable fire test is simulated with the newly proposed multi-particle-size model. The predicted smoke levels within the large enclosure of the fire test are compared with measured and observed values.

\section{Fire Experiment}

A large-scale PVC cable fire experiment in a U-shaped corridor was conducted by the Department of Fire Technology at SP Swedish National Testing and Research Institute with assistance from the University of Greenwich in 2006 [19-22]. The corridor had a total length of $44.6 \mathrm{~m}$ (centerline) (Fig. 3). The inner height of the corridor was $2.4 \mathrm{~m}$ and the inner width was $2.0 \mathrm{~m}$. At the inner corner, between the first and second corridor, a room of size $3.0 \mathrm{~m} \times 4.0 \mathrm{~m}$ was connected to the corridor through a $2 \mathrm{~m} \times 0.4 \mathrm{~m}$ opening at ceiling level. In the third corridor (exit corridor, from soffit \#3 to the exit), an exit was positioned below a calorimeter system making it possible to measure the heat release rate and collect smoke. The wall of the corridor and the ceiling of the room were covered with $10 \mathrm{~mm}$ Promatect- $\mathrm{H}$, noncombustible boards and the ceiling of corridor was covered with a $6 \mathrm{~mm}$ Masterboard, non-combustible board. The properties of those materials are described in detail in the SP report. The fire source consisted of an L-shaped cable tray arrangement with one vertical $(1.95 \mathrm{~m})$ and one horizontal $(1.8 \mathrm{~m})$ section. It was located about $3.9 \mathrm{~m}$ from the start of the first corridor, $0.25 \mathrm{~m}$ above the floor and $0.06 \mathrm{~m}$ from the corridor wall. The cable tray was ignited by a propane sand burner with size $0.1 \mathrm{~m} \times 0.4 \mathrm{~m} \times 0.1 \mathrm{~m}$. The burner had a heat output of approximately $30 \mathrm{~kW}$ and lasted for $30 \mathrm{~min}$. 
In order to record the fire development and the generation and transport of fire gases, extensive measurements were made along the corridor during the test. Temperatures were measured at various heights at locations with no. 2, 5, 7, etc (See Fig. 3). The smoke obscuration across the corridor was measured at a total of six positions at $2.2 \mathrm{~m}$ above the floor for positions no. 6, 9 and 10 (inside the corner room), and at $2.0 \mathrm{~m}$ above the floor at positions no. 12, 13 and 15 . In these positions, the lasers were mounted on one side of the corridor wall, giving a beam length of $2.0 \mathrm{~m}$, and detectors were mounted on the opposite wall. Four video cameras (V1-V4 in Fig. 3) were placed outside the corridor and faced into the corridor through glass to record the smoke movement; which were positioned about $0.5 \mathrm{~m}$ above the floor except for Camera V3 which was placed $1.3 \mathrm{~m}$ above the floor. In order to clearly see the smoke filling, reflective markings were mounted on poles along the corridor wall at position $6,9,12,13$ and 15 and two lights were located on the floor in the exit corridor.

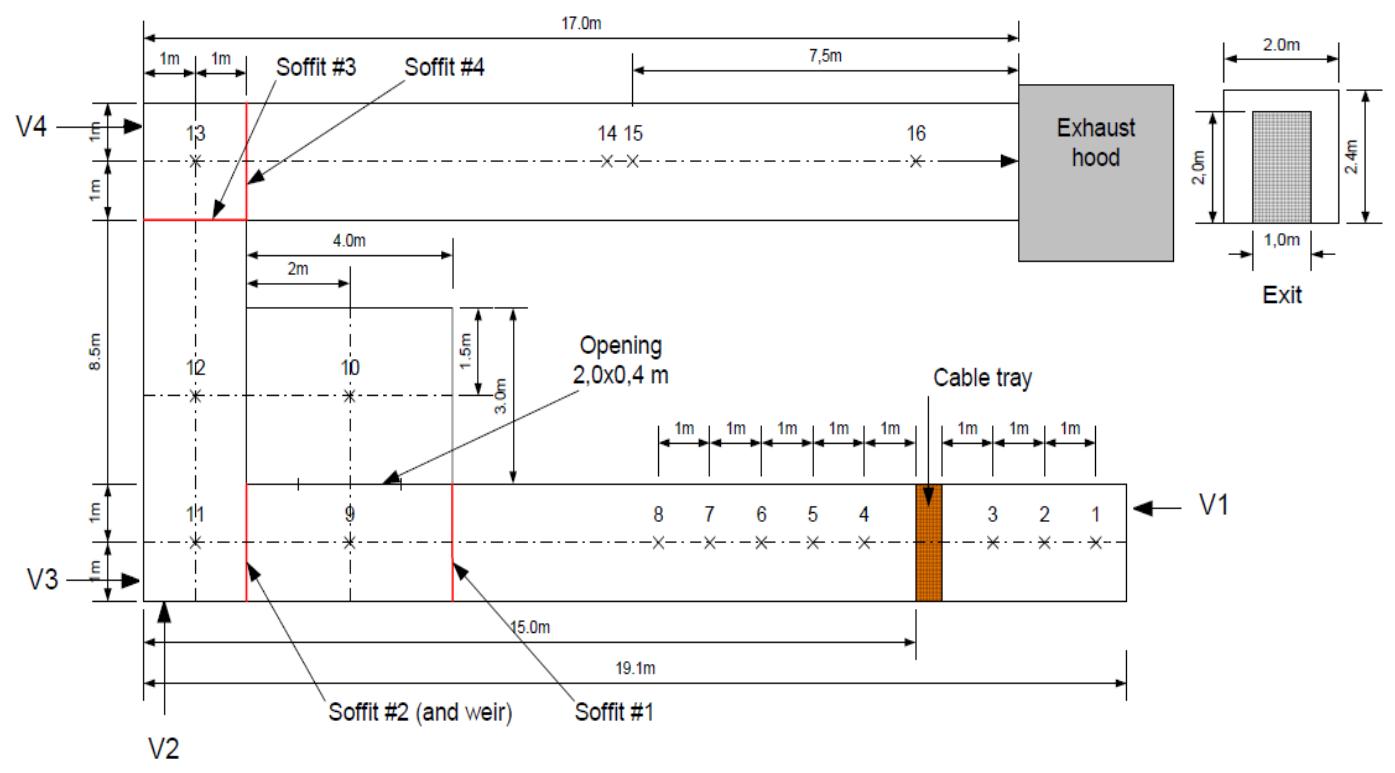

Fig. 3. General layout of the test corridor [19].

\section{Simulations}

A non-uniform Cartesian mesh consisting of 132,411 cells was used in the discretization of the geometry. For mesh sensitive analysis, a finer mesh consisting of 573,000 cells was also created. The variation of the predicted peak temperatures at position 5 from simulations with the two meshes is less than $1.7 \%$. The results showed here are therefore of the coarser mesh.

The cable used in the fire test was made of PVC material which contains pure PVC, plasticizer and chalk. The basic molecular structure of the fuel is assumed to be $\mathrm{C}_{2} \mathrm{H}_{3} \mathrm{Cl}$ (pure PVC) as in the simulation in [20]. In this simulation, the eddy dissipation combustion model [23] is used to generate the heat due to combustion. The average heat of combustion during the fire test and used in the simulation is $9.66 \mathrm{MJ} / \mathrm{Kg}$, which is derived from the measured fuel loss rate and heat release rate. The mass loss rate curve derived from the measured load cell data is given in Fig. 4. A multi-ray radiation model is used to represent the exchange of heat due to radiation.

The mechanisms of smoke production are very complex and outside the scope of the present study. Therefore, the generation of smoke is not modeled and a constant smoke emission factor of 0.12 is instead applied in this study to calculate the total smoke generation rate, i.e., the smoke generation rate is the product the fuel loss rate and the smoke emission factor [7]. The smoke is simply treated as a volumetric particle source, in which the three prescribed groups of smoke particles of the three different sizes as described previously are generated. The mass fractions of particles in the three particle-size groups defined in the multi-particle-size model for PVC cable are $0.69,0.24$ and 0.06 respectively, which are derived from the mass size distribution of this cable in Fig. 1. The smoke sources for the three particle equations are the 
product of the total smoke generation rate and the mass fraction of smoke of each group. The deposition processes of particles on solid surfaces are complex, which is affected by thermophoresis, diffusion and gravitational force, etc. [16,24]. In this study, deposition velocities with various particle sizes from [16] are adopted.

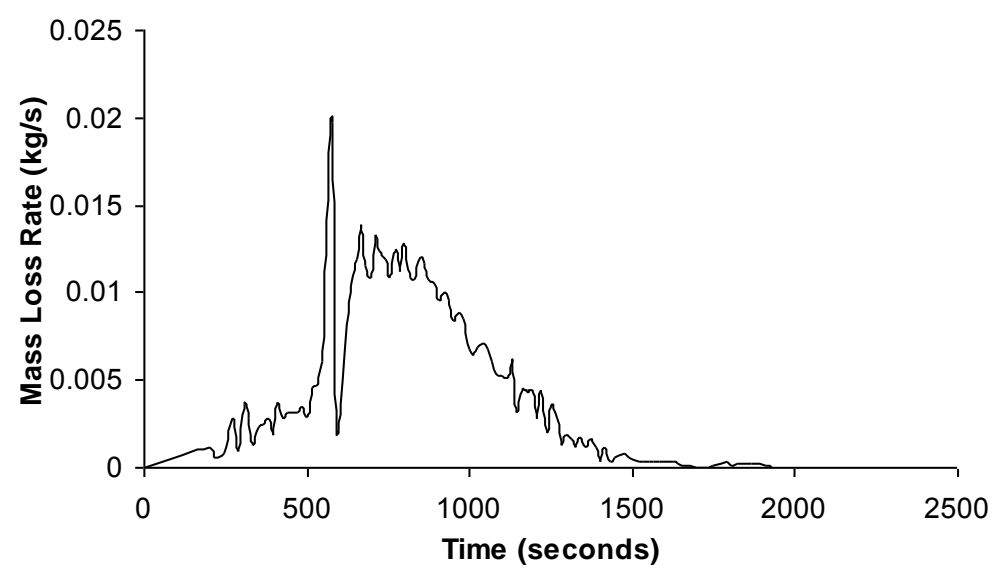

Fig. 4. The mass loss rate.

To complete the set up of the corridor fire scenario it is necessary to specify a proper set of boundary conditions. Within the present simulation, a wall emissivity of 0.8 is used for all solid surfaces. The thickness of the wall is those described previously. The density, conductivity, specific heat are $870 \mathrm{~kg} / \mathrm{m}^{3}$, $0.18 \mathrm{~W} / \mathrm{m} \cdot \mathrm{K}, 1130 \mathrm{~J} / \mathrm{kg} \cdot \mathrm{K}$ for Promatect $\mathrm{H}$, and are $1100 \mathrm{~kg} / \mathrm{m}^{3}, 0.22 \mathrm{~W} / \mathrm{m} \cdot \mathrm{K}$, and $1130 \mathrm{~J} / \mathrm{kg} \cdot \mathrm{K}$ for Masterboard respectively. At open boundaries, the solution domain is extended by some $2.1 \mathrm{~m}$. The ambient temperature is set to be $20^{\circ} \mathrm{C}$. As the $k-\varepsilon$ turbulence model is applicable only in regions with high Reynolds numbers, close to the walls, where viscous effects become dominant, wall functions are applied. Details of the wall functions implemented in SMARTFIRE can be found in [14].

The duration of the fire was approximately $1800 \mathrm{~s}$ and simulations are carried out with a time step size of $2 \mathrm{~s}$.

\section{Simulation Results}

The fire test was conducted within a large enclosure (the total length of the corridors is $44.6 \mathrm{~m}$ ), and it is very suitable to observe the smoke movement in weak turbulence environments, especially in the exit corridor. In the following discussion, the predictions of the multi-particle-size model and the conventional model are compared with the experimental data and observations at locations of interest. These are light extinction profiles at positions near the fire (position 6) and far away from the fire (position 15). Since the predicted smoke filling times in the first length of corridor produced by the two models are very close, visibility comparisons are only presented for the exit corridor, which is remote from the fire source.

\section{Smoke Predictions}

Firstly, the measured light extinction properties are compared with those derived from the smoke predictions. Using Eq. 6, the light extinctions can be calculated by using the predicted smoke concentrations from the conventional model and the multi-particle-size model. Figure 5 shows the measured and predicted light extinctions at $2.2 \mathrm{~m}$ above the floor at position 6 (near the fire) and $2.0 \mathrm{~m}$ above the floor at position 15 (far away from the fire). The measured light extinctions decrease from $100 \%$ to nearly $0 \%$ very rapidly from $3.3 \mathrm{~min}$ to $4.2 \mathrm{~min}$ at position 6 and from $5.6 \mathrm{~min}$ to $7.8 \mathrm{~min}$ at position 15 . As seen in Fig. 5, the predictions of the two smoke models are in very good agreement with the measured data.

Secondly, the calculated visibility at the lower layer in the exit corridor is compared with the experimental observations. The visibility distance referred in the latter discussion starts from Camera V4 which is pointed towards the exit. In the experiment, Camera V4 was placed at the start of the exit corridor, opposite 
to the exit (See Fig. 3 for position) and the distance between Camera V4 and the light source near the exit was $17 \mathrm{~m}$. Camera V4 recorded that the light source became very dim at about $9 \mathrm{~min}$ and was completely obscured at about $10.6 \mathrm{~min}$. For the remaining $20 \mathrm{~min}$, the light source remained completely obscured. Therefore, in the experiment, the visibility distance remained less than $17 \mathrm{~m}$ after $10.6 \mathrm{~min}$. In the simulations, the visibility is calculated based on the average concentration of smoke between Camera V4 and the light source at $0.3 \mathrm{~m}$ above the floor. In Eq. 8, the constant $C$ takes the value 8 as the light used in the experiment is much brighter than that of common exit signs. Figure 6 shows the predicted visibility distances from 7 min onwards. The conventional model predicted a visibility distance of less than $17 \mathrm{~m}$ only after $20 \mathrm{~min}$, which is approximately $9.4 \mathrm{~min}$ later than the observed obscuration time, an overprediction of $89 \%$. Furthermore, the conventional model predicts that the period of obscuration of the light source lasts for only $1.5 \mathrm{~min}$ and then the predicted visibility distance becomes greater than $17 \mathrm{~m}$, indicating that the light source is again visible. However, the visibility distance derived from the multiparticle-size model decreases to $17 \mathrm{~m}$ at approximately $8 \mathrm{~min}$, an under-prediction of $25 \%$. Considering that the light source used in the test was much brighter than those used for common exit signs, the constant value of 8 in Eq. 8 used in the calculation may be too low for the source used in the experiment. The calculated visibility distance therefore decreases more quickly than it should be. With this in mind, the predicted time of $8 \mathrm{~min}$ is in reasonably good agreement with the measured time of $10.6 \mathrm{~min}$.

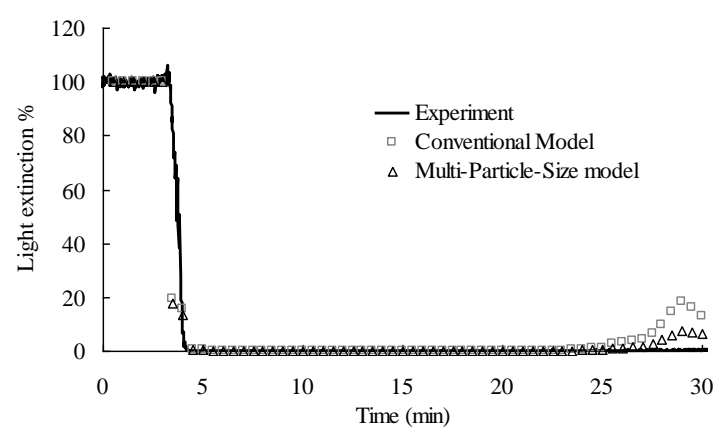

(a)

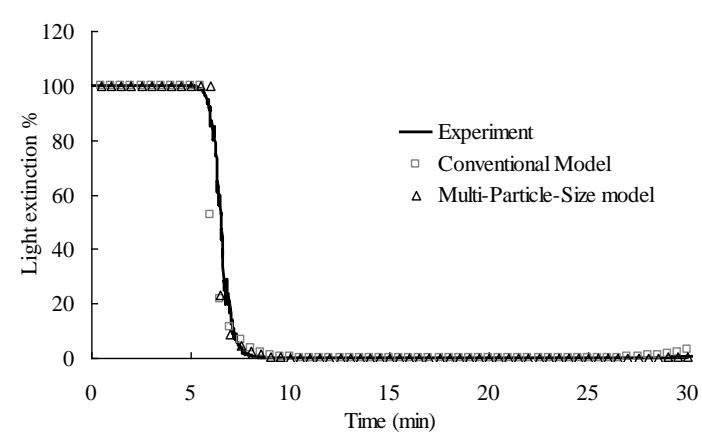

(b)

Fig. 5. The measured and predicted light extinction: (a) position 6; (b) position 15.

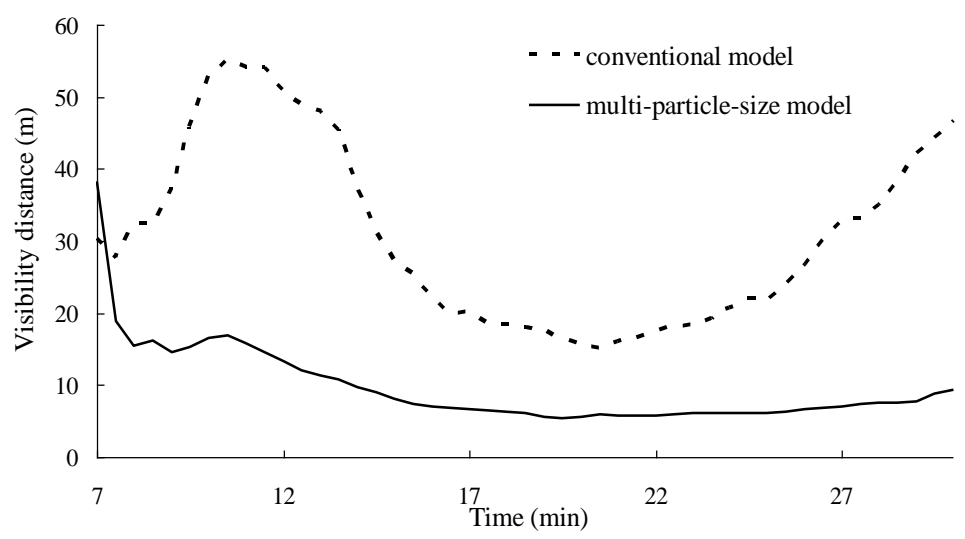

Fig. 6. Predicted visibility distance from Camera V4 to the light source near the exit.

It is noted that the predicted visibility distance at $0.3 \mathrm{~m}$ above the floor for the conventional model does not decrease monotonically with time, particularly between 8 to $15 \mathrm{~min}$ into the fire. Locations at $0.3 \mathrm{~m}$ above the floor in the exit corridor are in the lower layer, i.e., below the neutral plane. At this height, the stream of incoming fresh air dilutes species concentrations. As seen in Fig. 4, the fire develops gradually for the first $8 \mathrm{~min}$ followed by a rapid growth and remains at quite high heat release rates up to $15 \mathrm{~min}$ into the fire. Thus the incoming flow of air from 8 to $15 \mathrm{~min}$ into the fire is stronger $(0.25 \mathrm{~m} / \mathrm{s}$ on average) than the incoming flow in the first $8 \mathrm{~min}(0.20 \mathrm{~m} / \mathrm{s}$ on average $)$ of the fire. As the conventional model treats smoke 
as a gas, the source of smoke in the lower layer is generated solely through the mixing of the upper layer, rich with combustion products, with the lower layer. The stronger incoming flow leads to lower smoke concentrations after $8 \mathrm{~min}$ and hence higher visibility distances. In the multi-particle-size model however, the gravitational effect of smoke particles produces an additional source of smoke for the lower layer due to the downward movement of smoke particles. As a result, the diluting effect of the incoming air flow on smoke concentration is less pronounced. Therefore, in the multi-particle-size model, the predicted smoke mass fractions at $0.3 \mathrm{~m}$ above the floor are higher than those for the conventional model and so the predicted visibility distances during the period when the fire is strong ( 8 to $15 \mathrm{~min}$ ) only suffers some slight fluctuations with a much smaller increase than that in the conventional model predictions.

Thirdly, the predicted smoke filling times in the exit corridor are compared with the experimental observations. In the experiment, reflective markings were mounted on a pole at position 15 with a vertical spacing of $0.5 \mathrm{~m}$ and starting from $0.5 \mathrm{~m}$ above the floor (Fig. 7a). Here we select the obscuration times for the markings for comparison between the model predictions and observed smoke movement. Figure $7 \mathrm{~b}$ shows that after $9.5 \mathrm{~min}$, all the markings on the pole at position 15 are no loner visible.

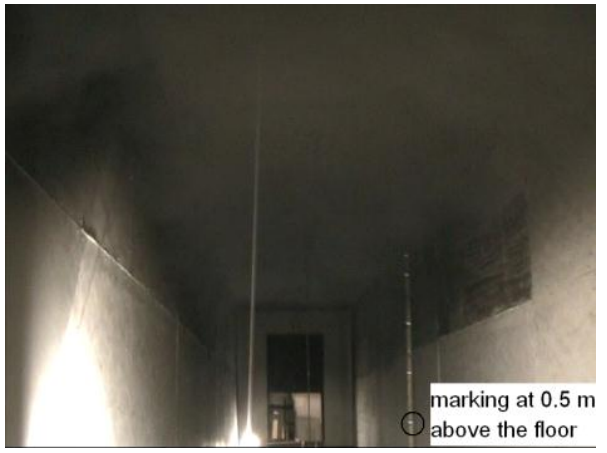

(a)

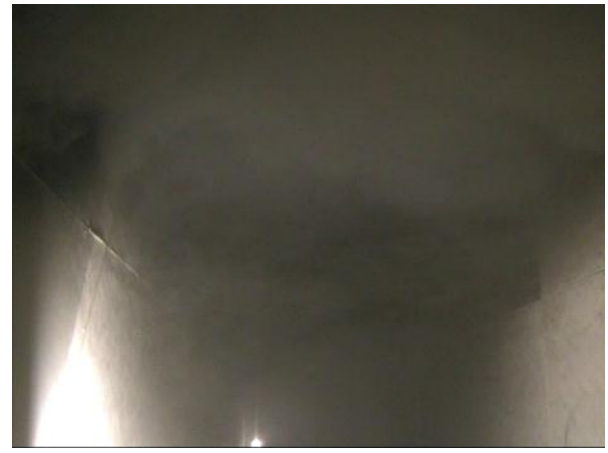

(b)

Fig. 7. Observed smoke movement in the exit corridor: (a) 6 min; (b) 9.5 min.

Table 1 gives the observed and predicted obscuration time of each marking at position 15. The observed times are approximately estimated from the video recording. From Table 1, it is clear that the predictions of the obscuration times for both models are in good agreement with the observed times in the upper layer ( $1.0 \mathrm{~m}$ above the floor). However, the conventional model predicts the marking in the lower layer $(0.5 \mathrm{~m}$ above the floor) remained visible 7.6 min longer than the observation in the test, an over-prediction of $81 \%$ while the prediction from the multi-particle-size model is only $1.6 \mathrm{~min}$ longer, or an over-prediction of only $17 \%$.

Table 1. Obscuration times (min) of the markings at position 15.

\begin{tabular}{|c|c|c|c|}
\hline Position of markings & Observation & $\begin{array}{c}\text { Conventional } \\
\text { model }\end{array}$ & $\begin{array}{c}\text { Multi-particle-size } \\
\text { model }\end{array}$ \\
\hline $0.5 \mathrm{~m}$ above the floor & 9.4 & 17 & 11 \\
\hline $1.0 \mathrm{~m}$ above the floor & 8.3 & 7.6 & 7.8 \\
\hline $1.5 \mathrm{~m}$ above the floor & 7.5 & 7.2 & 7.2 \\
\hline $2.0 \mathrm{~m}$ above the floor & 6.8 & 5.8 & 5.9 \\
\hline
\end{tabular}

The visibility distances as functions of time at $1.5 \mathrm{~m}$ and $0.5 \mathrm{~m}$ above the floor respectively are shown in Fig. 8. The visibility distances in the upper layer derived from both models are very close to each other (see Fig. 8a), however, those in the lower layer show significant differences (see Fig. 8b). The distance between Camera V4 and the markings is nearly $10 \mathrm{~m}$. In Fig. 8b, the predicted visibility distances derived from the conventional model show that the marking at $0.5 \mathrm{~m}$ above the floor remains visible until $17 \mathrm{~min}$ and its obscuration only lasts for $5 \mathrm{~min}$. However, in the experiment the markings were obscured at about $9.4 \mathrm{~min}$ and did not become visible until the end of the test. The predictions with the multi-particle-size model successfully reproduce this observed phenomenon. 
Figure 9 presents the predicted iso-surfaces of smoke concentrations predicted by the two smoke models with a value of $0.000088 \mathrm{~kg} / \mathrm{m}^{3}$ at $12 \mathrm{~min}$ in the exit corridor. With smoke concentrations at this value, the visibility distance calculated from Eq. 8 with constant $C$ value of 8 is $10 \mathrm{~m}$. As seen in Fig. 9a, the marking at $0.5 \mathrm{~m}$ above the floor is obscured by this iso-surface while the marking in Fig. $9 \mathrm{~b}$ is much lower than the iso-surface. At $0.5 \mathrm{~m}$ above the floor, the average smoke concentration from Camera V4 to the marking derived from the multi-particle-size model is higher than $0.000088 \mathrm{~kg} / \mathrm{m}^{3}$ indicating a visibility distance less than $10 \mathrm{~m}$. On the other hand, the marking is below the iso-surface predicted by the conventional model, indicating the marking is visible from Camera V4 at this time.

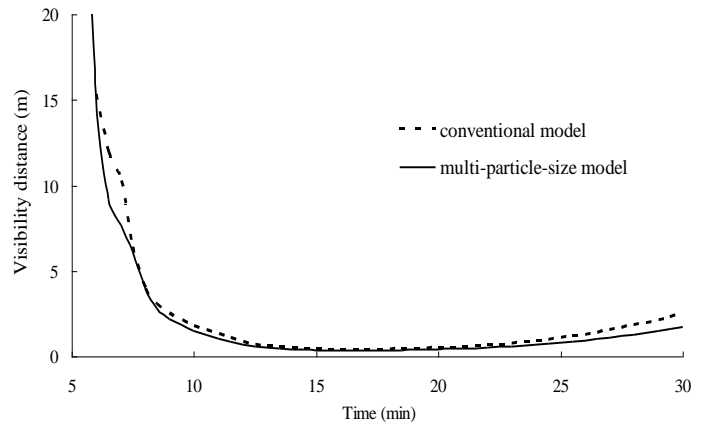

(a)

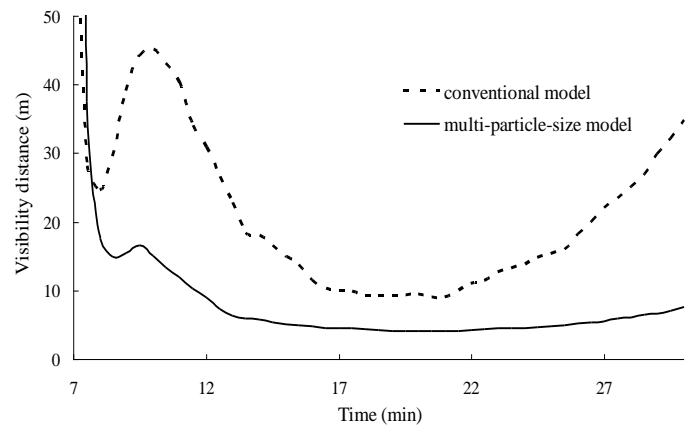

(b)

Fig. 8. Predicted visibility distances for markings: (a) $1.5 \mathrm{~m}$; (b) $0.5 \mathrm{~m}$ above the floor at position 15 .

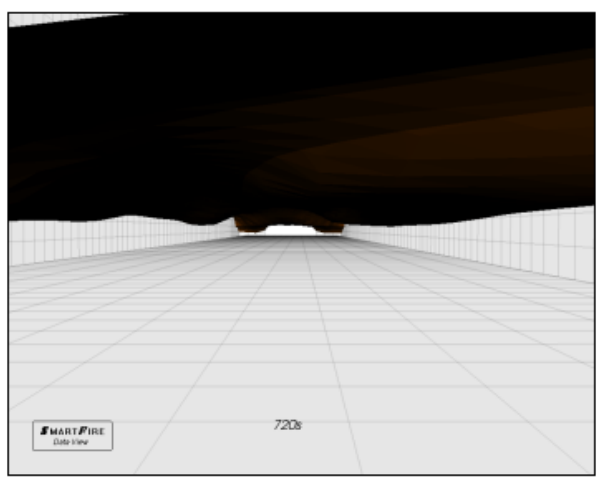

(a)

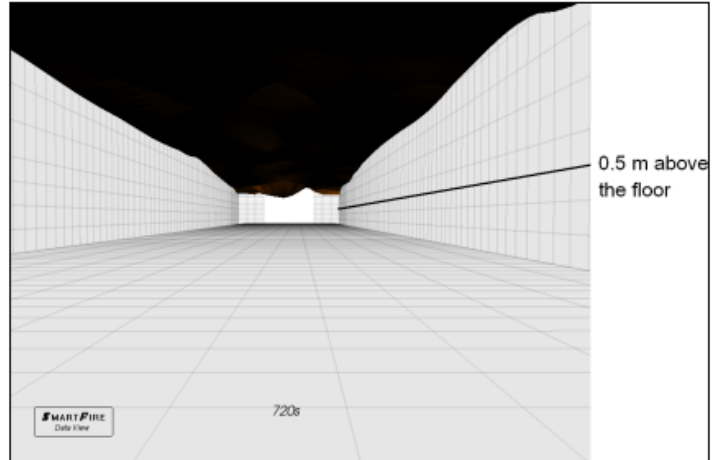

(b)

Fig. 9. Predicted iso-surface of smoke concentration in the exit corridor at 12 min: (a) multi-particle-size model; (b) conventional model.

\section{Deficiency of Using Temperature to Estimate Smoke Levels}

Finally, the deficiency of using temperature to estimate smoke levels is highlighted. At position 15, the measured temperatures at $2.2 \mathrm{~m}$ above the floor are as high as $40{ }^{\circ} \mathrm{C}$, while they are close to the ambient value of $21.0{ }^{\circ} \mathrm{C}$ at $1.0 \mathrm{~m}$ above the floor during the entire $30 \mathrm{~min}$ of the test time (see Fig. 10). Based on the method of using temperature to estimate smoke levels in [4], the visibilities at the two different heights at $12 \mathrm{~min}$ are approximately $4.8 \mathrm{~m}$ and over $88.8 \mathrm{~m}$ respectively.

It is clear that the smoke layer predicted from this approach is at least $1.0 \mathrm{~m}$ above the floor, the height of the lower thermocouple at position 15. Furthermore, the predicted visibility distance, based on the measured peak temperature at $1.0 \mathrm{~m}$ above the floor during the entire 30 minute test period, is more than $10 \mathrm{~m}$, which suggests that the marking at this height is always visible during the entire simulation. However, as observed in the experiment and predicted by the multi-particle-size model, the smoke layer moves below the marking at position 15 in the lower layer, $0.5 \mathrm{~m}$ above the floor, within $12 \mathrm{~min}$. This difference between the temperature estimation method and the experimental observation highlights the deficiency of that 
approach. Before smoke moves to remote locations, a lot of heat has already been lost via radiation or through the confining walls. Therefore, temperature is not a good indicator to the smoke movement at remote locations.

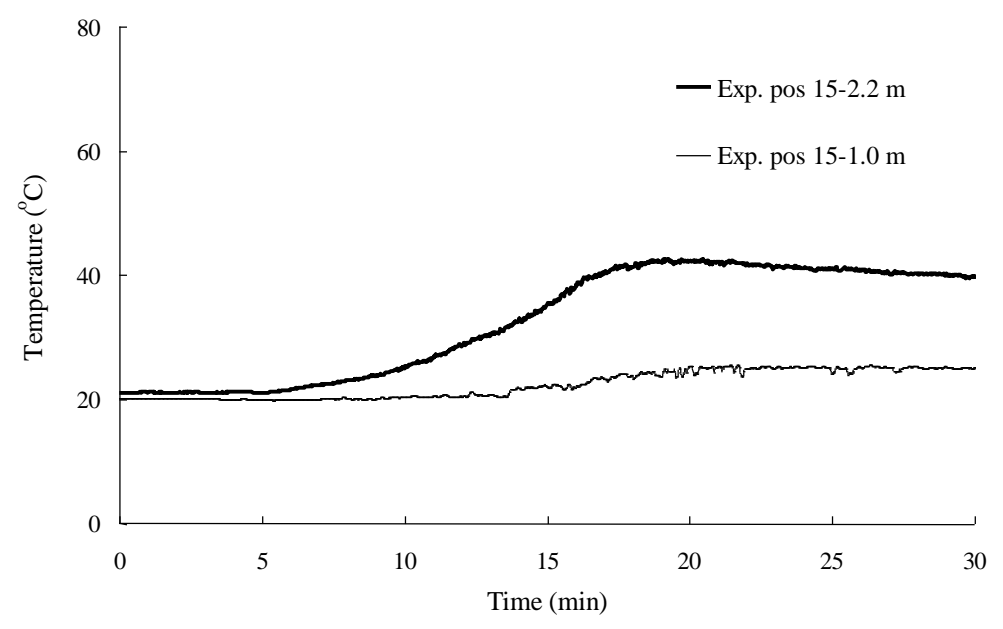

Fig. 10. Measured temperatures at position 15.

\section{Discussion}

There are several issues relating to the implementation of the multi-particle-size model that need to be considered. Firstly, in this model, the particles are divided into three groups for smoke concentration calculation, with particle sizes in the range of less than $2.0 \mu \mathrm{m}$, between $2.0 \mu \mathrm{m}$ and $7.0 \mu \mathrm{m}$ and greater than $7.0 \mu \mathrm{m}$ respectively. This group division method is based on the observed particle mass distributions for materials in Fig. 1. In order to examine the reliability of this methodology, a finer division including 10 groups with particle sizes between $0.1 \mu \mathrm{m}$ and $10 \mu \mathrm{m}$ are investigated for this PVC cable fire. The predicted smoke mass fractions along the vertical line at position 15 at 12 min from the multi-particle-size model with 3 and 10 smoke groups are compared in Fig. 11. The predictions with the two different smoke group divisions are very close, especially in the lower layer. It shows that the use of three groups for categorizing smoke particles are adequate to reflect the effect of smoke particle size on the transportation of smoke for PVC cable fires. The increase of the group number in the multi-particle-size model might improve the predictions precisions to a certain degree but it also involves expensive computational requirement. Three groups might be an adequate compromise between the cost and accuracy of the model. Most of the materials listed in Fig. 1 have similar mass size distributions, so the current smoke group division criterion is expected to perform well in the simulation of smoke movement for these materials.

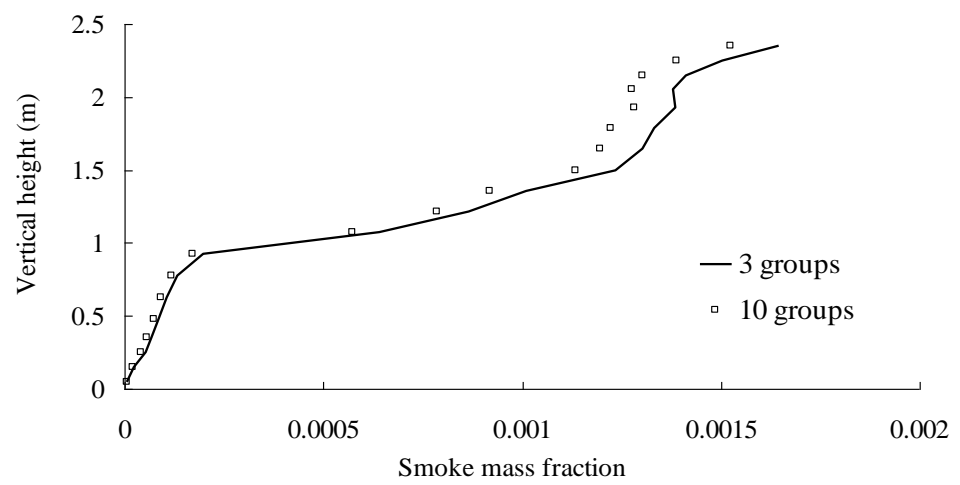

Fig. 11. Predicted smoke mass fractions along vertical line at position 15 at 12 min with different particle group divisions. 
Secondly, compared to the conventional model, two additional conservation equations must be solved in the multi-particle-size model when three particle groups are represented. This increase in the number of governing equations incurs additional computational costs. Furthermore, some additional computational effort is required for the convection correction for each of the three conservation equations associated with each particle group. The $1800 \mathrm{~s}$ simulation of the PVC cable fire scenario, involving 132,411 computational cells was carried out using a computer with a $3.0 \mathrm{GHz}$ processor and a memory of $4.0 \mathrm{~GB}$. Using the conventional model, the simulations required approximately $60 \mathrm{~h}$. The simulation using the multi-particle-size model took approximately $8 \%$ longer - a modest increase in computational time for the improved accuracy.

Thirdly, the coagulation process [10], which would effectively reduce the number of smallest particles and increase the sizes of smoke particles during the course of transportation, is not considered in this study. Increases in the sizes of smoke particles might make the gravitational force a more important mechanism in smoke transport and enhance the downwards movement of smoke. In the above simulation results, the obscuration times of the markings in the upper layer are predicted slightly earlier than what was observed in the test while they are delayed by nearly $2 \mathrm{~min}$ in the lower layer (Table 1). The lack of representing coagulation in the smoke model might play a part in the differences between the predictions and the observations of the obscuration timings of the markings in the upper and lower layers. The effect of coagulation on smoke movement will be investigated in the further refinement of the multi-particle-size model.

\section{CONCLUSION}

As the majority of particles within smoke are smaller than $2 \mu \mathrm{m}$, the effects of gravitational forces on these smoke particles are negligible and hence often neglected in smoke transport models. However, the smoke particle mass distributions cover diameter sizes between $0.01 \mu \mathrm{m}$ and $10 \mu \mathrm{m}$ and the mass fractions of particles above $7 \mu \mathrm{m}$ can be as high as 0.06 for many building materials. Due to the effect of gravitational forces on these larger smoke particles, smoke transportation behaves differently to the transportation of fire gases. In this paper, a multi-particle-size model has been developed to take into account the settling velocity of large smoke particles. In the newly developed model, smoke particles are divided into three groups in terms of their sizes and their transport is represented by three conservation equations, in which the effect of gravitational force on smoke movement due to particle sizes is considered.

The newly developed multi-particle-size model was examined by simulating a large-scale PVC cable fire experiment. In the upper layer, the predicted light extinction by both the newly developed model and the conventional model, are in good agreement with the measured experimental data. The predicted obscuration times of reflecting makings at $2.0 \mathrm{~m}, 1.5 \mathrm{~m}$ and $1.0 \mathrm{~m}$ above the floor by the two models are also similar and both are in good agreement with the observed times. However, the conventional model over-predicted the experimental obscuration time for the markings $0.5 \mathrm{~m}$ above the floor (which was $9.4 \mathrm{~min}$ ) by $81 \%$ (17 min) while the newly developed model over-predicted the obscuration time by only $17 \%(11 \mathrm{~min})$. The measured obscuration time for the light source in the corner near the exit was observed to be $10.6 \mathrm{~min}$ in the experiment. Here again the newly developed model more accurately predicted the observed obscuration time. The conventional model over-predicted this time by $89 \%$ (20 min) while the newly developed model under-predicted this time by $25 \%(8 \mathrm{~min})$. These results show that the multiparticle-size model greatly improves the prediction precision for the smoke movement in the lower layer compared with the conventional model.

Compared with the conventional model, the newly developed multi-particle-size model requires an additional $8 \%$ of computational cost for the PVC cable fire simulation.

The present study also reveals the deficiency of estimating smoke levels from temperatures. The predicted smoke layer using the temperatures in the exit corridor is at least $1.0 \mathrm{~m}$ above the floor during the entire simulation time while the observed smoke layer descends below $0.5 \mathrm{~m}$ above the floor within $12 \mathrm{~min}$. Therefore, it is potentially problematic to represent the smoke layer by the hot layer at remote regions from the fire source.

While the multi-particle-size model appears promising, further validation is required involving more experimental data, especially the light extinction data at lower layers. The group division method also 
needs to be further assessed for different materials. Furthermore, in this study, the size of each particle is assumed to be constant. The change of particle size due to coagulation will be addressed in future work.

\section{ACKNOWLEDGMENTS}

Ms Hu would like to thank FSEG of the University of Greenwich for their financial support through the PhD Bursary Programme.

\section{REFERENCES}

[1] National Statistics, "Fire statistics United Kingdom 2005" Department for Communities and Local Government Report 06FRSD04395, London, 2007.

[2] Hertzberg, T., Blomqvist, P. and Tuovinen, H., (2007) Reconstruction of an arson hospital fire, Fire and Materials 31(4): 225-240, http://dx.doi.org/10.1002/fam.935

[3] Hertzberg, T. and Blomqvist, P., (2003) Particles from fires-a screening of common materials found in buildings, Fire and Materials 27(6): 295-314, http://dx.doi.org/10.1002/fam.837

[4] Soren, I., Bror, P. and Heimo, T., "Simulation of smoke detection in a room with a perforated suspended ceiling," the 8th international Fire Science \& Engineering Conference, Interflam, Interscience Communications, 1999, pp. 441-452.

[5] Rubini, P.A., Zhang, Q. and Moss, J.B., "Numerical simulation of visibility in smoke laden environments," the 11th international Fire Science \& Engineering Conference, Interflam, Interscience Communication, 2007, pp. 490-499.

[6] Galea, E.R., Wang, Z., Veeraswamy, A., Jia, F., Lawrence, P. J. and Ewer, J., (2008) Coupled fire/evacuation analysis of station nightclub fire, Fire Safety Science 9: 465-476. http://dx.doi.org/10.3801/IAFSS.FSS.9-465

[7] George, W.M., "Smoke Production and Properties," The SFPE Handbook of Fire Protection Engineering ( $2^{\text {nd }}$ ed.), National Fire Protection Association, Quincy, MA 02269, 1995, pp. 2/217$2 / 227$.

[8] Chen, F., Yu, S., and Lai, A., (2006) Modeling particle distribution and deposition in indoor environments with a new drift-flux model, Atmospheric Environment 40(2): 357-367, http://dx.doi.org/10.1016/j.atmosenv.2005.09.044

[9] Murakami, S., Kato, S., Nagano, S. and Tanaka, Y., (1992) Diffusion Characteristics of Airborne Particles with Gravitational Settling in a Convection-dominant Indoor Flow Field, ASHRAE Transactions 98: 82-97.

[10] Butler, K. and Mulholland, G., (2004) Generation and Transport of Smoke Components, Fire Technology 40(2): 149-176, http://dx.doi.org/10.1023/B:FIRE.0000016841.07530.64

[11] Rhodes, J., Smith, C., and Stec, A., (2011) Characterisation of soot particulates from fire retarded and nanocomposite materials, and their toxicological impact, Polymer Degradation and Stability 96(3): 277-284, http://dx.doi.org/10.1016/j.polymdegradstab.2010.07.002

[12] Chow, W., (2004) A new model on simulating smoke transport with computational fluid $\begin{array}{llll}\text { dynamics, } & \text { Building } & \text { 39(6): }\end{array}$ http://dx.doi.org/10.1016/j.buildenv.2003.12.012

[13] Zhao, B., Yang, C., Yang, X., and Liu, S., (2008) Particle dispersion and deposition in ventilated rooms: Testing and evaluation of different Eulerian and Lagrangian models, Building and Environment 43(4): 388-397, http://dx.doi.org/10.1016/j.buildenv.2007.01.005

[14] Ewer, J., Grandison, A., Jia, F, Galea, E.R., Knight, B. and Patel, M., User Guide and Technical Manual, SMARTFIRE V4.1, The University of Greenwich, U.K., 2007. 
[15] Ewer, J., Galea, E., Patel, M., Taylor, S., Knight, B., and Petridis, M., (1999) SMARTFIRE: an Intelligent CFD Based Fire Model, Journal of Fire Protection Engineering 10(1): 13-27, http://dx.doi.org/10.1177/104239159901000102

[16] Alvin, C.K.L. and William, W.N., (2000) Modeling Indoor Particle Deposition from Turbulent Flow onto Smooth Surfaces, Journal of Aerosol Science 31: 436-476. http://dx.doi.org/10.1016/S0021-8502(99)00536-4

[17] Dietrich, W., (1982) Settling velocity of natural particles, Water Resources Research 18(6): 1615, http://dx.doi.org/10.1029/WR018i006p01615

[18] Jin, T., (1981) Visibility Through Fire Smoke, Journal of Fire and Flammability 9: 135-155.

[19] Persson, H., "Labyrinth Project Full Scale Tests in a Corridor Arrangement," SP Swedish National Testing and Research Institute Report BRs 6119, Sweden, 2006.

[20] Mahalingam, A., Modeling the Generation of Toxic Combustion Products and its Transport in Enclosure Fires, PhD thesis, University of Greenwich, U.K., 2007.

[21] Mahalingam, A., Jia, F., Patel, M.K. and Galea, E.R., "Modelling Generation and Transport of Toxic Combustion Products in Enclosure Fires using Bench-Scale Test Data," the 11th International Fire Science \& Engineering Conference, Interflam, Interscience Communication, 2007, pp. 1631-1636.

[22] Robinson, J.E., Hull, T.R., Lebek, K., Stec, A.A., Galea, E.R., Mahalingam, A., Jia, F., Patel, M.K., Persson, H. and Journeaux, T., "Assessment of the Impact of Computed and Measured Fire Environments on Building Evacuation using Bench and Real Scale Test Data," the 11th International Fire Science \& Engineering Conference, Interflam, Interscience Communication, 2007, pp. 873-884.

[23] Magnussen, B., (1977) On mathematical modeling of turbulent combustion with special emphasis on soot formation and combustion, Symposium (International) on Combustion 16(1): 719-729, http://dx.doi.org/10.1016/S0082-0784(77)80366-4

[24] Jason, F. and Randy, M., "Modeling Soot Deposition Using Large Eddy Simulation with a Mixture Fraction Based Framework," $12^{\text {th }}$ International Fire Science \& Engineering Conference, Interflam, Interscience Communication, 2010, pp. 755-764. 